Bangladesh J. Zool. 48(2): 263-288, 2020

ISSN: 0304-9027

eISSN: $2408-8455$

\title{
FIRST DISTRIBUTIONAL RECORD OF SIXTEEN CORAL ASSOCIATED FISH SPECIES FROM SAINT MARTIN'S ISLAND, BANGLADESH
}

\author{
Shilpi Saha ${ }^{1}$, Shamsunnahar ${ }^{1}$, Subrina Sehrin ${ }^{1}$, Anirban Sarker ${ }^{1}$, Kazi Ahsan \\ $\mathrm{Habib}^{2}$ and Mohammad Abdul Baki ${ }^{*}$ \\ Department of Zoology, Jagannath University, Dhaka, Dhaka-1100, Bangladesh
}

\begin{abstract}
The Bangladeshi reef fish species have not been studied thoroughly. An attempt has been made for taxonomic identification of coral-associated fish through morphological studies. Mostly dead and few live fishes were collected from local fishermen, fish landing zone, and fish markets in St. Martin's Island, Bay of Bengal, Bangladesh, from October 2015 to July 2016, visiting seven times. Samples were also obtained from local boys who collected fishes by using hook and line. The study recorded the first occurrence of 16 coral-associated fish species such as Caesio cuning, Lethrinus ornatus, Upeneus suahelicus, Upeneus asymmetricus, Scarus taeniopterus, Scarus zufar, Bodianus neilli, Parapercis clathrata, Parapercis diplospilus, Pomadasys furcatus, Siganus fuscescens, Acanthopagrus berda, Gerres erythrourus, Lagocephalus spadiceus, Psettodes bennettii, and Heteroconger perissodon. Among them, Parapercis clathrata, Parapercis diplospilus belongs to the family Pinguipedidae before, no species was recorded under this family from Bangladesh and a rare and endemic species, Scarus zufar, of the Arabian Sea off Dhofar (Zufar), Oman in the Western Indian Ocean, was recorded for the first time in the Northern Indian Ocean in the northeastern part of Bay of Bengal. This study increased the number of coralassociated fish from 240 to 256 species and the number of families from 54 to 55 in the coral reef ecosystem of the Bay of Bengal, Bangladesh.

Key words: Coral ecosystem, morphomeristics, Parapercis clathrata, Parapercis diplospilus, Scarus zufar
\end{abstract}

\section{INTRODUCTION}

St. Martin's Island is the only coral island of Bangladesh. Tourism has been increased deliberately, which is posing a threat to the island and its biodiversity, although Bangladesh Government has declared this island as an Ecologically Critical Area (ECA) in 1999. However, very few taxonomic studies have been conducted on the diversity of coral associated fish species in the northeastern part of the Bay of Bengal, Bangladesh. Tomascik (1997) found 86 species

*Author for corresponding: <mabaki@gmail.com>, 2Department of Fisheries, Sher-e-Bangla Agricultural University, Dhaka, Bangladesh.

C2020 Zoological Society of Bangladesh DOI: https://doi.org/ 10.3329/bjz.v48i2.52368 
belonging to 34 families. Shafi and Quddus (2003) reported 14 species belonging to 11 families. By checking the habitat status, 147 species belonging to 50 families were compiled from Rahman et al. (2009). Sarker et al. (2015) found 26 species belonging to 11 families. Saha et al. (2018) recorded two Lutjanus species and established a new extended distributional area. Recently, Saha et al. (2019) reported two goatfish species of the genus Upeneus. By combining the described fish species list in the above-mentioned literature, a total of 240 species belonging to 54 families were compiled as the coral-associated fish species diversity list. The present study was conducted to establish the total number of fish species in the coral ecosystem of St. Martin's Island, Bay of Bengal, Bangladesh, to extend the checklist to the data-poor area and implement improved monitoring efforts and conservation management plans.

\section{MATERIAL AND METHODS}

Sample collection: Fish specimens were collected from local fishers in the fish landing zones and fish market of the St. Martin's Island (Fig. 1) $\left(20^{\circ} 34^{\prime} \mathrm{N}\right.$ $20^{\circ} 38.8^{\prime} \mathrm{N}$ and $92^{\circ} 18^{\prime} \mathrm{E}-92^{\circ} 20.8^{\prime} \mathrm{E}$ ) from October 2015 to July 2016. Fishers caught these fishes by using gill net, ber jal, and hooks and lines, and local young boys who used hook and line. The specimens were preserved in a cool box and transferred at $-20{ }^{\circ} \mathrm{C}$ in the Fisheries Laboratory, Department of Zoology, Jagannath University, Dhaka, until further study. All specimens were kept in the museum of the Zoology Department, Jagannath University, as voucher specimens after completing the study. Morphological studies: The fish length was measured in centimeter to the nearest 0.01 , and weight was measured in gram. Together with descriptive characters such as shape, size, and coloration, about 33 Morphometrics and 12 meristic characters were used for the identification of each species. Morphometric and meristic methods followed to Allen and Talbot (1985). Meristic and morphometric abbreviations are as follows: D, dorsal fin; $\mathrm{D}_{1}$, first dorsal fin; $\mathrm{D}_{2}$, second dorsal fin; $\mathrm{A}$, anal fin spines and rays; $\mathrm{P}$, pectoral fin rays; $\mathrm{V}$, pelvic fin spines and rays; $\mathrm{C}$, caudal fin rays; $\mathrm{Li}$, scales in lateral line; aLi, scales above lateral line; bLi, scales below lateral line; uGr, gill raker on upper series; $1 \mathrm{Gr}$, gill raker on lower series; br, branched; ubr, unbranched; TW, total weight; TL, total length; SL, standard length; HL, head length; BW, body width; BD, body depth; BL, barbel length; CPD, caudal peduncle depth; CPL, caudal peduncle length; $\mathrm{CC}$, caudal concavity; CBL, caudal fin base length; PDL, pre dorsal length; PAL, pre anal length; PPL, pre pectoral length; PVL, pre pelvic length; DBL, dorsal fin base length; LDS, longest dorsal spine; LaDS, last 

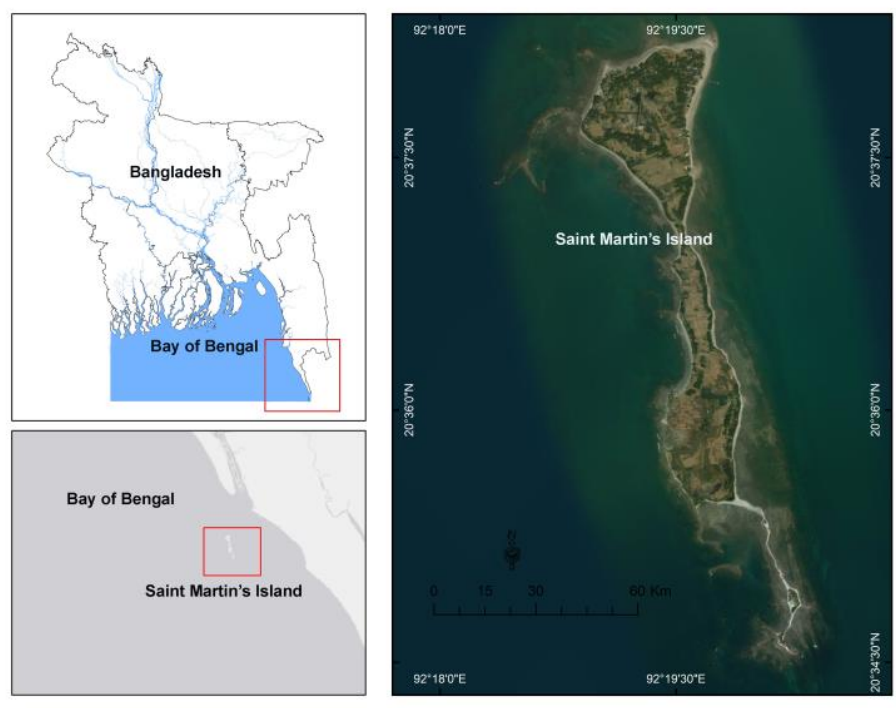

Fig. 1. Map of St. Martin's Island, Bay of Bengal, Bangladesh showing the location of the sample sites of 17 newly recorded coral fish species.

dorsal spine; LDR, longest dorsal ray length; ABL, anal fin base length; LAS, longest anal spine; LaAS, last anal spine; LArL, longest anal fin ray length; PBL, pectoral fin base length; LPrL, longest pectoral fin ray length; VBL, pelvic fin base length; LVrL, longest pelvic fin ray length; IOL, inter orbital length; PrOL, pre orbital length; PoOL, post orbital length; ED, eye diameter; SnL, snout length; UJL, upper jaw length; LJL, lower jaw length; jaw gape (JG). The morphomeristics study was carried out in the Fisheries Laboratory, Department of Zoology, Jagannath University, Dhaka-1100, Bangladesh.

\section{RESULTS AND DISCUSSION}

A total of 67 species of coral-associated fish belonging to 41 genera, 32 families, and eight orders (Perciformes, Tetraodontiformes, Aulopiformes Siluriformes, Beryciformes, Scorpaeniformes, Pleuronectiformes, and Anguilliformes) were identified on the bases of morphometrics and meristics studies. Among the eight orders, Perciformes was the dominant and includes 23 families, 30 genera, and 55 species. Tetraodontiformes includes two families, three genera, and four species. Aulopiformes includes one family, two genera, and three species. Pleuronectiformes includes two families, two genera, and two 
species. Siluriformes, Beryciformes, Scorpaeniformes, and Anguilliformes has one species each.

The 16 previously unreported species from St. Martin's Island represented 13 families, including Caesionidae, Lethrinidae, Mullidae, Scaridae, Labridae, Pinguipedidae, Haemulidae, Siganidae, Sparidae, Gerreidae, Tetraodontidae, Psettodidae, and Congridae. Sixteen of the new St. Martin's Island species (Caesio cuning, Lethrinus ornatus, Upeneus suahelicus, Upeneus asymmetricus, Scarus taeniopterus, Scarus zufar, Bodianus neilli, Parapercis clathrata, Parapercis diplospilus, Pomadasys furcatus, Siganus fuscescens, Acanthopagrus berda, Gerres erythrourus, Lagocephalus spadiceus, Psettodes bennettii, and Heteroconger perissodon) have relatively cosmopolitan regional distributions and are expected to occur in St. Martin's Island, except for Scarus zufar Randall and Hoover 1995, which was previously found from three adult specimens collected in the Arabian Sea off Dhofar (Zufar), the southern province of Oman as endemism of the area. At first, reported from the northern Indian Ocean: Bay of Bengal, St. Martin's Island, Bangladesh. The present study confirmed the new distributional records of 16 coral-associated fish species in the coral ecosystem of St. Martin's Island. The details on the morphometric measurements for the holotypes of all the above-mentioned species are shown in Table 1.

\section{Caesio cuning (Bloch 1791) (Fig. 2A), locally called Holaddia.}

Holotype: F0416SM92, male, $12.8 \mathrm{~cm}$ standard length; collected on April 20, 2016.

Diagnosis: Characterized by a supratemporal band of scales confluent at the dorsal midline (Fig. 3A). Head length 3.12 in standard length, Allen and Erdmann (2012) found 2.8-3.6. The body depth was 2.46 in standard length, whereas that reported by Carpenter (1987) was 2.2-3.4. D, X/16 br; P, 19; V, I/5 br; A, III/12; C, 17; Li, 51; aLi, 8; bLi, 15; and $\mathrm{Br} 4$. D, X/14-16; P, 17-20; V, I/5; A, III/10-12; Li, 45-51; aLi, 8-9; and bLi, 15-17 according to Carpenter (1987).

Description: The body is deep, laterally flatten with convex dorsal outline, and moderate in size. The head is small and blunt. The mouth is rounded, protractile with a large mouth gap, and positioned termino-terminally. The jaws are large and equal. Only one post maxillary process occurs, the rear edge of the maxilla obtuse, and its greatest depth behind to the edge of the premaxilla. Cardiform teeth are present on both jaws, palatine, and vomer. The operculum, 
along with the flap and has a large opercular aperture. Only one lateral line is completed and curved. Large, circular ctenoid scales are overlapped. A single, large dorsal fin is residing in the middle of the body, originating from the middle of the pectoral and arriving just opposite of the anal fin, with spines anteriorly. The scales cover half of the dorsal fin height (Fig. 3B). Large and dagger-shaped pectoral fin positioned ventrolaterally, the pelvic fin is also large and placed in front. The large anal fin has spines onward, the forked, and heterocercal caudal fin with a shorter lower lobe.

Color: The body is light yellowish in the dorsal portion and light pinkish and whitish in the ventral portion. The head is light greenish. The spinous portion of the yellowish dorsal fin has a black tip membrane. The pectoral fin is orange yellowish and reddish at the base with a small triangular black spot at the upper basal portion. The pelvic and anal fins are light reddish. The caudal fin and caudal peduncle are yellow.

Habitat and Distribution: This reef-associated species (Fricke et al. 2011) is mainly found in the tropical eastern Indian Ocean to the Western Pacific, from Sri Lanka to Vanuatu, and from Southern Japan to Northwestern and Northeastern Australia (Carpenter 1987).

\section{Lethrinus ornatus (Valenciennes 1830) (Fig. 2B), locally called Ota.}

Holotype: F0416SM84, male, $8.6 \mathrm{~cm}$ standard length, and collected on April 20, 2016.

Diagnosis: Characterized by the red posterior margin of preopercle and opercle. Body depth is 2.61 in standard length. Matsunuma et al. (2011) reported 2.3-2.6; D, X/9 br; P, 12; V, I/5; A, III/8; C, 17; Li, 47; aLi 6; bLi, 13; $\mathrm{Br}, 3$; uGr, 4; and $1 \mathrm{Gr}, 7$. According to Matsunuma et al. (2011), D, X/9 br; P, 13; V, I/5; A, III/8; Li, 46-47; and aLi 6.

Description: The elongated and laterally flatten medium-sized body with a convex dorsal outline. The large and pointed head has large, oblique terminal mouth. The dorsal profile of the snout around the eye is convex. Jaws are large and equal. Cardiform and molariform teeth are present on both jaws, 12 cardiform and eight molariforms on the upper jaw, and 18 cardiform and six molariforms on the lower jaw. The large operculum, together with the flap, cover the large opercular aperture. The single lateral line is completed and curved. The large and circular ctenoid scales are overlapped. No scales are observed on the cheek. The single large dorsal fin is residing in the middle of the body, with 
spines anteriorly. The large and dagger-shaped pectoral fin is positioned ventrolateral
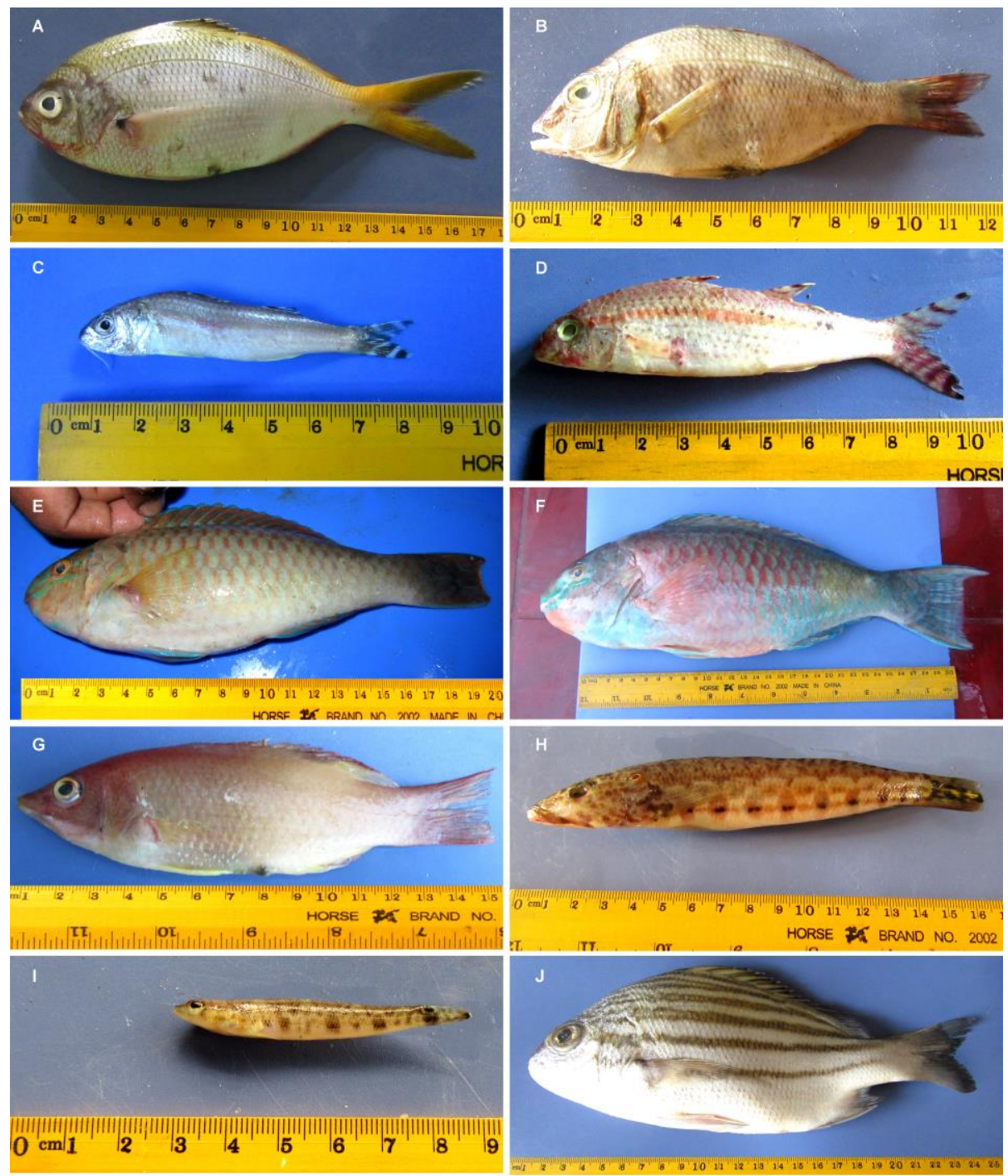

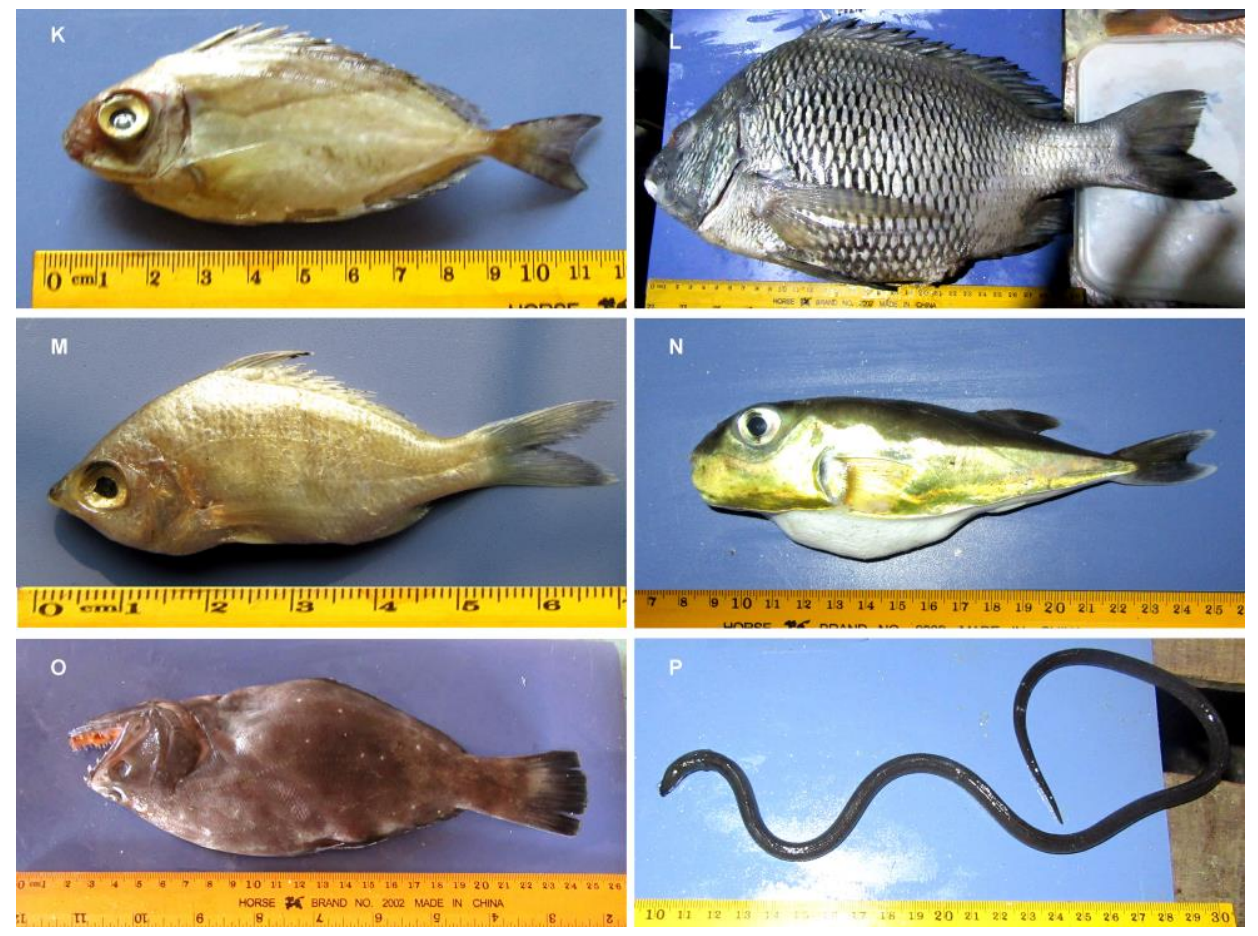

Fig. 2. Seventeen newly recorded fish species from the coral ecosystem of St. Martin's Island, Bay of Bengal, Bangladesh. (A) C. cuning $(12.8 \mathrm{~cm} \mathrm{SL})$, (B) L. ornatus, $(8.60 \mathrm{~cm} \mathrm{SL})$ (C) U. suahelicus $(7.00$ cm SL), (D) U. asymmetricus (8.50 cm SL), (E) S. taeniopterus $(16.2 \mathrm{~cm} \mathrm{SL}),(\mathrm{F})$ S. zufar $(29.0 \mathrm{~cm} \mathrm{SL})$, (G) B. neilli (12.1 cm SL), (H) P. clathrata (12.5 cm SL), (I) P. diplospilus (4.50 cm SL), (J) P. furcatus (18.7 cm SL), (K) S. fuscescens (9.80 cm SL), (L) A. berda, (M) Gerres erythrourus (5.00 cm SL), (N) $L$. spadiceus (13.0 cm SL), (O) P. bennettii (19.5 cm SL), and (P) H. perissodon $(41.0 \mathrm{~cm} \mathrm{SL})$.

The inner surface of the pectoral fin base is scaled. It has six longitudinal scale rows (including small scale beneath the dorsal fin base) between the lateral line onward. The large anal fin has spines in front, the forked and heterocercal caudal fin with a slightly larger upper lobe.

Color: The dorsal part of the body is yellowish, and the ventral part is brownish with five longitudinal yellow stripes. The head is blackish with a red spot on the lower front edge of the eye. The dorsal fin is black, and the tip is red. The pectoral and pelvic fins are yellowish. The anal fin is light yellow, and the base is whitish. The caudal fin is reddish and yellowish at the base.

and the base of the middle spine of the dorsal fin. The large pelvic fin is placed Habitat and Distribution: This reef-associated species (Myers 1999) is found in Indo-West Pacific: Maldives (Anderson et al. 1998) and Sri Lanka to the Ryukyu 
Islands, Papua New Guinea, and Northeast Australia. Reported from Vietnam but probably a misidentification (Kuronuma 1961).

Upeneus suahelicus (Uiblein and Heemstra 2010) (Fig. 2C), locally called Beta.

Holotype: F0416SM16, male, $7.0 \mathrm{~cm}$ standard length, and together with 14 other individuals (6.5- $8 \mathrm{~cm}$ standard length) collected on April 20, 2016.

Diagnosis: It is identified by two pale brown midlateral body stripes and four oblique bars on the upper caudal-fin lobe and four on the lower. HL 3.18 in SL, CPD 11.6 in SL, BL 5.8 in SL, HL 3.18 in SL, CPD 11.6 in SL, and BL 4.6-6.6 in SL reported by Uiblein and Heemstra (2010). $\mathrm{D}_{1}$, VII; $\mathrm{D}_{2}$, I/9 br; P, 17; A, I/7 br; C, $13 \mathrm{br}$; Li, 31; aLi, 3; bLi, 5; Br, 2 pair. According to Uiblein and Heemstra (2010), $\mathrm{D}_{1}$, VII; $\mathrm{D}_{2}$, I/9; P, 15-16; A, I/7; and Li, 34-35.

Description: The elongated, laterally flatten, dorsally slightly convex, and medium-sized body has small and obtuse head. The large, rounded, and protractile mouth is placed terminally with a large mouth gap. Equal jaws are

with very small conical teeth that also present on palatine and vomer. Two barbels are found on the chin. The single lateral line is complete and straight. The large and triangular ctenoid scales are overlapped. Two disconnected, medium-sized dorsal fins begin from the lower $1 / 3$ of the pectoral fin and arrive just opposite to the end of the anal fin. The $1^{\text {st }}$ dorsal fin spinous and $2^{\text {nd }}$ dorsal fin with soft ray has a single spine anteriorly. The large, dagger-shaped pectoral fin is positioned ventrolaterally, and the medium-sized pelvic fin is situated onward. The medium-sized anal fin has spines anteriorly, and the caudal fin is forked and homocercal.

Color: The body is reddish-brown dorsally and silver ventrally. Two pale brown stripes are present in the body, one stripe from behind the head to the caudal fin base, where it joins the proximal upper caudal-fin lobe bar, and the other stripe below the pectoral fin base to the caudal peduncle and continued to the proximal-most lower caudal fin lobe bar. The head is light yellowish. In both Dorsal fins, black stripes are observed in the white membrane, and the tip of $\mathrm{D}_{1}$ is black (Fig. 3C). White pectoral, light reddish pelvic, light yellowish anal fin are observed. Eight bars are found on the caudal fin, four dark brown bars on the upper caudal-fin lobe, and four bars on the lower lobe, increasing distally in width. Interspaces are white and narrower than the bar. Barbels are white. Habitat \& Distribution: Reef-associated. Western Indian Ocean 


\section{Upeneus asymmetricus (Lachner 1954) (Fig. 2D), locally called Lal Mas.}

Holotype: F0216SM25, female, $8.5 \mathrm{~cm}$ standard length; collected on February $17,2016$.

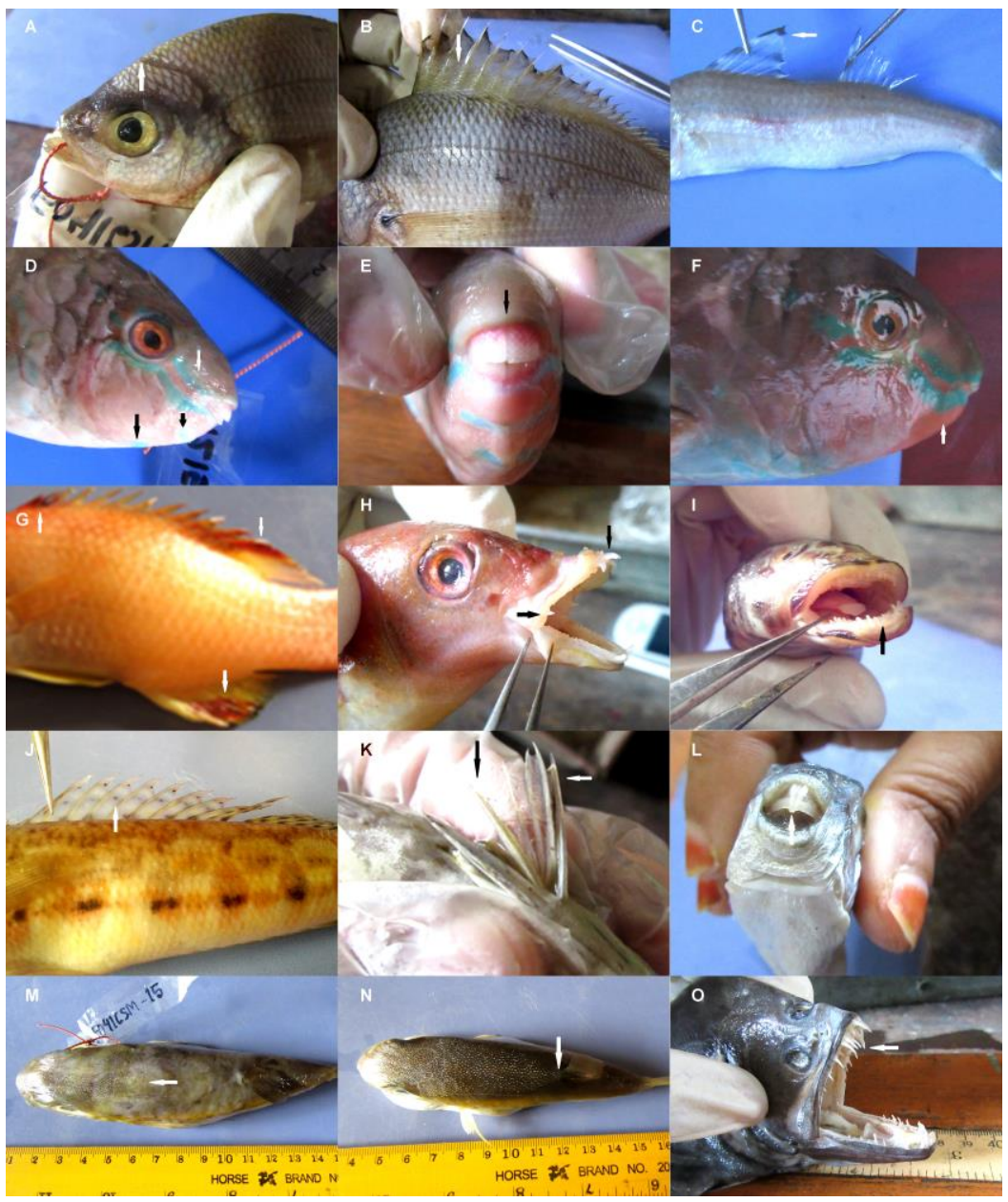

Fig. 3. Identification of the morphological characteristics of the newly recorded coral-associated fish species. (A) Continuous supratemporal band of scales in C. cuning, (B) Scales cover half of the dorsal fin height in C. cuning, (C) Blacktip in D1 of U. suahelicus, (D) Two blue-green stripes on the head above and below the eye and two blue-green bands on the chin of $S$. taeniopterus, (E) Teeth fused into a beak-like plate in S. taeniopterus, (F) Orange chin of S. zufar, (G) Two red patches on the dorsal fin and a red patch with a small black spot in the middle of the anal fin in B. neilli, $(\mathrm{H})$ Anterior canines and posterior canine in B. neilli, (I) Recurved canine in P. clathrate, (J) Black spot on the dorsal fin of P. clathrata, (K) The pelvic fin of $S$. fuscescens with II spines (one inner and one strong outer spine, with three soft rays in between), (L) Beak-like teeth in L. spadiceus, (M) A patch of spinules on the back between the snout and halfway to the dorsal fin origin in L. spadiceus, (N) A patch of spinules on the back from behind the nostril to the dorsal-fin origin in Lagocephalus lunaris, $(\mathrm{O})$ Large canine teeth in $P$. bennettii 
Kenya to South Africa, Eritrea (Red Sea) (Uiblein and Heemstra 2010)

Diagnosis: Identified by three narrow oblique dark bars on the upper lobe and six on the lower part of the caudal fin, and with a midlateral dark stripe on the body. $\mathrm{D}_{1}$, VII; $\mathrm{D}_{2}, 8$; P, 13; A, I/6 br; C, 14 br; Li, 31; aLi, 2; bLi, 5; and $\mathrm{Br}, 2$ pair. Kim and Nakaya (2002) reported $\mathrm{D}_{1}$, VII; P, 13-14; Li, 29-31.

Description: The elongated, laterally flatten, dorsally slightly convex, and moderate-sized body has small and blunt head. The inferior mouth is large, oblique, slightly protractile, and with a largemouth gap. Unequal jaws are with very small conical teeth. Chin has two barbels, just reaching the posterior margin of the preopercle. Two spines present at the end of the operculum. A single lateral line is completed and slightly curved. Large and pentagonal ctenoid scales are overlapped. Two segregated dorsal fins originating from $1 / 4$ of the pectoral fin and arrive just opposite to the end of the anal fin, $1^{\text {st }}$ dorsal fin spinous. The large and dagger-shaped pectoral fin positioned ventrolaterally. The small pelvic fin is placed anteriorly. The small anal fin has spines anteriorly, and the caudal fin is forked and heterocercal.

Color: The body is light reddish dorsally and whitish ventrally. A midlateral dark red stripe is present from behind the eye to the middle base of the caudal fin. A

dark brown saddle-like spot is present on the caudal peduncle just posterior to the $\mathrm{D}_{2}$. The head is light yellowish. White barbels on the chin and two dark red stripes with white interspaces are found on both dorsal fins. The pectoral and pelvic fins are yellowish, and the anal fin is whitish. Three narrow oblique dark red bars are found on the upper lobe of the caudal fin and six on the lower lobe, increasing distally in width. The interspaces between the bars of the upper caudal-fin lobe are wider than the bars and white in color, but those in the lower lobe are narrower and light reddish in color.

Habitat and Distribution: They are found in rocky reefs and sand patches among reefs from 5-100 m depth. They are Indo-West Pacific species found in the Re

Sea and the Indo-Australian Archipelago, reported as a Lessepsian migrant from the Red Sea in the Eastern Mediterranean - Lebanon and Israel (Por 1978).

Scarus taeniopterus (Lesson 1829) (Fig. 2E), locally called Tota or Baro Sundori.

Holotype: F1215SM01, male, $16.2 \mathrm{~cm}$ standard length; collected on December 14, 2015. 
Diagnosis: Identified by two narrow blue-green stripes in the head, one through the upper part of the eye and one through the lower part of the eye (Fig. 3D). Body depth 2.89 in standard length while 2.6-2.9 by Robins and Ray (1986). D, IX/ 10 br; P, 14; V, I/5 br; A, III/9; C, 15 br; Li, 24; aLi, 2; bLi, 6; Br,

\begin{tabular}{|c|c|c|c|c|c|c|c|c|c|c|c|c|c|c|c|c|}
\hline & $\begin{array}{c}c . \\
\text { cuning }\end{array}$ & $\begin{array}{c}L \text { L } \\
\text { ornatus }\end{array}$ & $\begin{array}{l}\text { U. } \\
\text { suahelicus }\end{array}$ & $\underset{\text { asymmetricus }}{U .}$ & $\begin{array}{c}\text { S. } \\
\text { taeniopterus }\end{array}$ & $\begin{array}{c}S . \\
\text { zutar }\end{array}$ & $\begin{array}{c}\text { B. } \\
\text { neili }\end{array}$ & $\begin{array}{c}P . \\
\text { clathrata }\end{array}$ & $\begin{array}{c}P . \\
\text { diplospilus }\end{array}$ & $\begin{array}{c}P . \\
\text { furcatus }\end{array}$ & $\begin{array}{c}\text { S. } \\
\text { fuscescens }\end{array}$ & $\begin{array}{c}\text { A. } \\
\text { berda }\end{array}$ & $\begin{array}{c}G . \\
\text { abbreviatus }\end{array}$ & $\underset{\text { spadiceus }}{L}$ & $\begin{array}{c}P_{.} \\
\text {bennettii }\end{array}$ & $\begin{array}{l}H_{\text {perissodon }} \\
\text { per }\end{array}$ \\
\hline $\mathrm{BW}(\mathrm{gm})$ & 66.8 & 21.1 & 5.50 & 50.0 & 110 & & & & & & 20.0 & 550 & 4.15 & 78.4 & 119 & 13.0 \\
\hline $\operatorname{TL}(\mathrm{cm})$ & 17.0 & 11.2 & 8.30 & 10.5 & 19.7 & 36.0 & 14.1 & 15.5 & 5.40 & 23.7 & 12.2 & 37.0 & 6.60 & 16.3 & 22.2 & 42.2 \\
\hline $\begin{array}{l}\text { SL (cm) } \\
\text { SL (\%) }\end{array}$ & 12.8 & 8.60 & 7.00 & 8.50 & 16.2 & 29.0 & 12.1 & 12.5 & 4.50 & 18.7 & 9.80 & . & 5.00 & 13.0 & 19.5 & 41.0 \\
\hline & 32.0 & 37.2 & 31.4 & 28.2 & 34.6 & 29.3 & 34.7 & 34.4 & 28.9 & 34.8 & 28.6 & . & 36.0 & 34.6 & 27.2 & 5.90 \\
\hline $\mathrm{BD}$ & 40.6 & 38.4 & 22.9 & 24.7 & 34.6 & 34.5 & 289 & 200 & 178 & 45.5 & 418 & . & 440 & 40.0 & 41.5 & 200 \\
\hline$B W$ & 16.4 & 15.1 & 11.4 & 14.1 & 179 & . & 140 & 192 & 178 & 176 & 122 & . & 180 & 238 & 974 & 146 \\
\hline CPD & 7.00 & 8.10 & 8.60 & 11.8 & 7.40 & & 14.1 & 6.40 & 8.90 & 13.4 & 5.10 & . & 140 & 7.69 & 4.10 & \\
\hline CPL & 9.40 & 18.6 & 18.6 & 23.5 & 14.8 & 10.3 & 22.3 & 9.60 & 11.1 & 12.3 & 9.18 & . & 16.0 & 26.9 & 10.8 & . \\
\hline CC & 16.5 & 10.5 & 10.0 & 12.9 & 1.23 & 8.62 & 3.31 & & & 6.40 & 10.2 & . & 30.0 & 9.23 & & . \\
\hline CBL & 12.5 & 14.0 & 11.4 & 11.8 & 15.4 & 17.6 & 14.9 & 11.2 & 11.1 & 15.0 & 10.2 & - & 14.0 & 8.46 & 13.8 & . \\
\hline PDL & 37.5 & 36.0 & 40.0 & 34.1 & 37.0 & 36.2 & 38.0 & 36.0 & 28.9 & 46.5 & 34.7 & - & 46.0 & 65.4 & 16.9 & - \\
\hline PAL & 58.6 & 65.1 & 62.9 & 64.7 & 64.8 & 69.0 & 59.5 & 512 & 44.4 & 74.9 & 54.1 & - & 72.0 & 64.6 & 37.9 & - \\
\hline $\begin{array}{l}\text { PPL } \\
\text { PVL }\end{array}$ & $\begin{array}{l}29.7 \\
367\end{array}$ & $\begin{array}{l}36.0 \\
419\end{array}$ & $\begin{array}{l}31.4 \\
314\end{array}$ & $\begin{array}{l}282 \\
282\end{array}$ & $\begin{array}{l}31.5 \\
333\end{array}$ & $\begin{array}{l}27.6 \\
362\end{array}$ & 34.7 & 35.2 & 31.1 & 34.2 & 29.6 & : & 38.0 & 37.7 & 28.7 & : \\
\hline $\begin{array}{l}\text { PVL } \\
\text { DBL }\end{array}$ & $\begin{array}{l}36.7 \\
54.7\end{array}$ & $\begin{array}{l}41.9 \\
52.3\end{array}$ & 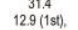 & $\begin{array}{c}28.2 \\
14.1 \text { (1st), }\end{array}$ & $\begin{array}{l}33.3 \\
58.6\end{array}$ & $\begin{array}{l}36.2 \\
58.6\end{array}$ & $\begin{array}{l}36.4 \\
48.8\end{array}$ & $\begin{array}{l}28.8 \\
68.0\end{array}$ & $\begin{array}{l}24.4 \\
71.1\end{array}$ & $\begin{array}{l}39.0 \\
59.9\end{array}$ & $\begin{array}{l}35.7 \\
65.3\end{array}$ & : & $\begin{array}{l}42.0 \\
54.0\end{array}$ & 9.23 & $\begin{array}{l}27.2 \\
68.2\end{array}$ & : \\
\hline LDS & 16.4 & 15.1 & $\begin{array}{l}12.9 \text { (2nd) } \\
18.6 \text { (1st) }\end{array}$ & $\begin{array}{l}14.1(2 \mathrm{nd}) \\
20.0(1 \mathrm{st})\end{array}$ & 9.90 (4th) & . & 14.0 & $6.40(3 \mathrm{rd})$ & 11.1 (4th) & 17.1 (4th) & 15.3 & . & $22.0(2 \mathrm{nd})$ & . & - & . \\
\hline & (4th) & (5th) & & & & & (7th) & & & & $\begin{array}{c}\left(4 \text { th }^{2}-8 \mathrm{ht}\right) \\
9918\end{array}$ & . & & & & . \\
\hline ABL & 219 & 20.9 & 12.9 & 11.8 & 25.9 & 22.4 & 21.5 & 44.8 & 48.9 & 17.1 & 41.8 & : & 18.0 & 7.69 & 52.3 & \\
\hline LAS & $\begin{array}{l}11.7 \\
(3 \mathrm{rd})\end{array}$ & $\begin{array}{l}11.6 \\
(2 n d \& 8 \\
3(d)\end{array}$ & 7.1 (1st) & 10.6 (1st) & $11.7(3 \mathrm{rd})$ & . & $\begin{array}{l}13.2 \\
(3 \mathrm{rd})\end{array}$ & 8.80 (1st) & 6.7 (115t) & $\begin{array}{l}18.2 \\
\text { (2nd) }\end{array}$ & $\begin{array}{c}15.3 \\
(3 \mathrm{rd} \& 4 \mathrm{th})\end{array}$ & - & 16.0(2nd) & 9.23 & . & . \\
\hline LaAS & & 128 & 114 & 153 & & & 174 & 104 & i11 & & 10.2 & : & 140 & 185 & & : \\
\hline $\begin{array}{l}\text { LAnL } \\
\text { PBL }\end{array}$ & 7.00 & $\begin{array}{l}128 \\
580\end{array}$ & $\begin{array}{l}11.4 \\
5.70\end{array}$ & $\begin{array}{l}15.3 \\
4.70\end{array}$ & $\begin{array}{l}212.3 \\
6.80\end{array}$ & $\begin{array}{l}17.2 \\
10.3\end{array}$ & $\begin{array}{l}1 / 4 \\
6.61\end{array}$ & $\begin{array}{l}10.4 \\
5.60\end{array}$ & 6.70 & $\begin{array}{l}70.2 \\
6.41\end{array}$ & $\begin{array}{l}7.14 \\
7.14\end{array}$ & : & $\begin{array}{l}74.00 \\
8.00\end{array}$ & $\begin{array}{l}78.5 \\
10.0\end{array}$ & $\begin{array}{l}3.099 \\
3.08\end{array}$ & : \\
\hline LPLL & 31.3 & 30.2 & 20.0 & 22.4 & $\begin{array}{l}2.00 \\
22.2\end{array}$ & 24.1 & 20.7 & 200 & 222 & $\begin{array}{l}0.44 \\
342\end{array}$ & $\begin{array}{l}1.14 \\
245\end{array}$ & : & $\begin{array}{l}0.0 \\
36.0\end{array}$ & 16.9 & 11.3 & : \\
\hline VBL. & 3.90 & 5.80 & 4.30 & 3.50 & 4.32 & 9.00 & $\begin{array}{l}4.13 \\
4.13\end{array}$ & 4.00 & 8.88 & 6.95 & 5.10 & - & 6.00 & & 205 & . \\
\hline LVtL & 20.3 & 18.6 & 15.7 & 20.0 & 19.1 & 17.2 & 19.8 & 21.6 & 24.4 & 26.2 & 18.4 & . & 26.0 & . & 9.74 & . \\
\hline 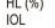 & 26.8 & 21.9 & 27.3 & 29.2 & 33.9 & & 26.2 & 11.6 & 769 & 292 & 286 & . & 389 & 422 & 132 & . \\
\hline PrOL & $\begin{array}{l}20.0 \\
220\end{array}$ & 34.4 & 31.8 & 29.2 & $\begin{array}{l}35.9 \\
35.7\end{array}$ & 35.3 & $\begin{array}{l}20.2 \\
33.3\end{array}$ & 30.2 & 30.8 & ${ }_{32.3}^{29.2}$ & $\begin{array}{l}30.0 \\
39.3\end{array}$ & : & 33.9. & $\begin{array}{l}42.2 \\
42.2\end{array}$ & $\begin{array}{l}13.2 \\
26.4\end{array}$ & . \\
\hline Pool & 51.2 & 37.5 & 40.9 & 37.5 & 48.2 & 47.1 & 47.6 & 48.8 & 38.5 & 46.2 & 32.1 & . & 44.4 & 28.9 & 54.7 & . \\
\hline ED & 26.8 & 28.1 & 22.7 & 25.0 & 17.9 & 17.6 & 21.4 & 18.6 & 308 & 262 & 429 & . & 333 & 31.1 & 15.1 & . \\
\hline SnL & 26.8 & 28.1 & 13.6 & 20.8 & 304 & . & 262 & 209 & 154 & 200 & 28.6 & . & 278 & 28.9 & 15.1 & . \\
\hline U.L & 34.1 & 34.4 & 36.4 & 37.5 & 26.8 & . & 35.7 & 372 & 38.5 & 29.2 & 25.0 & . & 33.3 & 26.7 & 69.8 & . \\
\hline LJL & 26.8 & 34.4 & 36.4 & 33.3 & 25.0 & . & 35.7 & 39.5 & 38.5 & 29.2 & 21.4 & - & 33.3 & 26.7 & 79.2 & - \\
\hline JG & 31.7 & 43.8 & 31.8 & 25.0 & 3.57 & . & 26.2 & 20.9 & 46.2 & 27.7 & 39.3 & . & 22.2 & 28.9 & 86.8 & . \\
\hline
\end{tabular}

4pair. According to Smith (1997), D, IX/10 br; A, III/9, and according to Robins and Ray (1986) P, 13-14; Li, 22-24.

Description: Large, elongated, and laterally compressed body is convex dorsally. The large and blunt head with medium-sized crescentic mouth that is positioned terminally. The small jaws are with an overbite (i.e., the front edge of a lower jaw inside the upper jaw when the mouth is closed). The lips are continuous with facial skin and without an indentation or fold. The teeth are fused to form beak-like plates (Fig. 3E) without the visible individual tooth. A small operculum with flap and a small opercular aperture is observed. A single lateral line is interrupted and straight. The large and irregular cycloid scales are overlapped. A large dorsal fin is situated near the head, originates from the base of the pectoral fin, and reaches up to the tail, with unexposed spines anteriorly. The large and elongated pectoral fin is situated ventrolaterally. The large pelvic fin present onward. The anal fin is large and has spines in front, and truncated caudal fin. 
Color: Greenish dorsally and bluish ventrally with a broad pale yellowish stripe anteriorly beneath the pectoral fin. The tip of each scale is orange, except in the ventral portion. The head is greenish in color. Two blue-green bands are present below the lower jaw (Fig. 3D). In the dorsal fin, blue, orange, blue, orange, and blue stripes are found from tip to base. The pectoral fin is yellowish with a reddish base. The pelvic fin is reddish, but the spinous portion is bluish. The color of the anal fin is similar to that of the dorsal fin. The caudal fin is blue, and the upper and lower edges are broadly bright orange.

Habitat and Distribution: This species is mainly found in the bottom with corals or rocks (Cervigon 1994) in Western Atlantic, Bermuda, Southern Florida (USA), and the Bahamas to Brazil; throughout the Caribbean (Randall 1978).

Remarks: S. taeniopterus is reported as ciguatera poisoning (Olsen et al. 1984) from the Eastern Caribbean. Locally, they are consumed as food, and larger ones are consumed by tourists. Hence, biochemical analysis is necessary to determine whether these species have ciguatera poisoning in the Bay of Bengal or not as this type of poisoning is a great threat to human health.

\section{Scarus zufar (Randall and Hoover 1995) (Fig. 2F), locally called Tota or Baro Sundori.}

Holotype: F0316SM01, male, $29 \mathrm{~cm}$ standard length; collected on March 15, 2016.

Diagnosis: Identified by a broad yellow patch on the anterior portion of the caudal peduncle. D, IX/10 br; P, 14; V, I/5; A, III/9; C, 13.

Description: The large and elongated body is laterally somewhat flattened and dorsally convex. The large and blunt head with a crescentic mouth terminally. Small jaws are with an overbite (the front edge of the lower jaw is inside the upper jaw when the mouth is closed). The lips are continuous with facial skin without an indentation or fold. The teeth are fused to form beak-like plates without a visible individual tooth. The operculum is small with a flap and with a small opercular aperture. An interrupted and straight lateral line is present. Large and irregular cycloid scales are overlapped. A large dorsal fin is situated near the head, which starts from the base of the pectoral fin and reaches up to the tail, with unexposed spines anteriorly. The large and elongated pectoral fin is situated ventrolaterally. The large pelvic fin is placed onward. The large anal fin has spines anteriorly and truncated caudal fin with pointed upper and lower marginal ray, where the upper ray is longer than the lower. 
Color: Its color is greenish dorsally and bluish and reddish ventrally with a broad yellow patch on and above the caudal peduncle. The tip of each scale is orange, and the base is greenish on the dorsal portion of the body, except a yellow patch portion. Its head is greenish in color, with orange chin (Fig. 3F). On the dorsal fin, blue, orange, blue, pink, and blue stripes are found from tip to base. The pectoral fin is orange, and the pelvic fin is orange, but the spinous portion is bluish. The color of the anal fin is like that of the dorsal fin. In the caudal fin, the pointed ray has a marginal blue stripe and then horizontal orange stripes. In the central portion, five blue-green bands alternate with five vertical pinkish bands are found.

Habitat and Distribution: This species is found in the Indian Ocean: known only from Oman (Randall and Hoover 1995).

\section{Bodianus neilli (Day 1867) (Fig. 2G), locally called Sundori.}

Holotype: F0416SM90, female, $12.1 \mathrm{~cm}$ standard length; collected on April 21, 2016.

Diagnosis: Identified by two dark red patches on the dorsal fin, one on the first three spinous portions and another on the last four spinous and first portions of the soft dorsal. A dark red patch with a small black spot in the middle of the anal fin was observed (Fig. 3G). Its body depth is 3.5, and head length is 2.9 in standard length. Gomon (2006) found the body depth to be 1.7 4.7 and head length to be 1.4-4.4 in standard length. D, XII/11 br; P, 15, $1^{\text {st }}$ two ubr; V, I/5 br; A, III/13; C, 12; Li, 35; aLi, 5; bLi, 7; Br, 3 pairs; uGr, 4; 1Gr, 8. According to Bloch (1790), D, XII, rarely XIII or XIV/ 9-11 usually 10; P, 13-16, $1^{\text {st }}$ two ubr; V, I/5; A, III rarely 0 or I/11-13 usually $12 ; \mathrm{C}, 9-12 ; \mathrm{Li}, 29-48 ; \mathrm{aLi}$, 3-71/2; bLi, 81/2-20; uGr, 4; 1Gr, 8.

Description: Its body is elongated, laterally flatten, dorsally convex, and moderate in size. Its head is medium in size and pointed. The mouth is large, oblique, and placed terminally with a large mouth gap (protractile). Both jaws are large, pointed, and equal. Both jaws have prominent four anterior canines, and then cardiform teeth are present. An enlarged posterior canine is also present (Fig. 3H). A lateral line is completed and slightly curved. The large and elongated cycloid scales are overlapped. A large dorsal fin with scaly base is placed in the middle of the body and with spines anteriorly. The pectoral fin is large, dagger-shaped, and situated ventrolaterally. The pelvic fin is medium in 
size and present onward. The large anal fin has spines anteriorly, and the caudal fin is emarginated.

Color: Its color is reddish dorsally and lightly reddish ventrally (after preservation in $-20{ }^{\circ} \mathrm{C}$ ), but pale rose-red anterodorsally (under fresh conditions). The head is reddish in color. A red patch is present at the anterior portion of the dorsal fin, middle yellowish, then another dark red patch, and lastly yellowish. The pectoral fin is pinkish, the pelvic fin is yellowish, and the anal fin is yellowish with a middle dark red spot and small black spots at the middle and reddish caudal fin.

Habitat and Distribution: The adults inhabit shallow coastal reefs and turbid lagoon reefs. They are apparently restricted to the coast of India, Sri Lanka, Maldive Island, and the Andaman Sea (Lieske and Myers 1994).

\section{Parapercis clathrata (Ogilby 1910) (Fig. 2H), local name Baila.}

Holotype: F0416SM91, male, $12.5 \mathrm{~cm}$ standard length; collected on April 21, 2016.

Diagnosis: A row of 12 elongated black spots around the reddish portion of the lower side of the body. D, IV/21; P, 16; V, I/5 br; A, I/ 17 br; C, 14 br; Li, 61; aLi, 6; bLi, 13; Br, 6 pair. According to Randall et al. (1990), D, IV/20-21; P, 14$21 ; \mathrm{Li}, 38-84 ; \mathrm{Br}, 6$ pairs.

Description: The body is elongated and cylindrical. Its dorsal profile is slightly convex and medium in size. The head is large and depressed to slightly pointed. The tip of the snout is flat with large eyes. Superior and oblique mouth with a medium mouth gap is observed. Recurved caniform teeth are present in an outer row at the front of the jaws (Fig. 3I), and cardiform teeth are found on palatine and vomer. One spine is present on the operculum. A lateral line is completed and straight. The scales are ctenoid, rhomboidal, large, and overlapping. A large dorsal fin originates from the opercular opening and reaches up to the base of the caudal fin, with spines onward. The large and elongated pectoral fin is positioned ventrolaterally. The large pelvic fin is situated anteriorly. The large anal fin has spines in front, and the caudal fin is truncated.

Color: The body is light greenish dorsally with red-colored 14 groups of snakelike stripes and light-brown ventrally. A conspicuous ocellus on each side of the nape is observed. The coloration of the ocellus is central red with a blue ring and then yellow around. A row of 12 elongated black spots around the reddish portion on the lower side of the body is observed. The head is olive-green with 
brown patches, and the cheek has many small black spots. Two narrow horizontal lines run from the pectoral fin origin to the caudal fin base. One line of dark gray spots, yellow band, dark gray spot, and small black spot is found on the dorsal fin (Fig. 3J) from base to the orange tip. The pectoral and pelvic fins are light gray with a chocolate-colored spot at the base of the pectoral. The anal fin has an orange tip and a white base, with an outer third gray with a row of elongated black spots. Two large yellow spots with four rows surrounding black spots are found in the middle of the caudal fin and at the lower base small orange spots present.

Habitat and Distribution: This marine, reef-associated species is found at a depth of 3-50 m (Myers 1991). Indo-West Pacific: India and Sri Lanka to Tonga, Ryukyu Islands, and the Great Barrier Reef to the Marshall Islands and Samoa (Randall et al. 2003).

\section{Parapercis diplospilus (Gomon 1981) (Fig. 2I); local name is Baila.}

Holotype: F0416SM75, male, $4.5 \mathrm{~cm}$ standard length, and with single another individual (4.2 cm standard length) collected on April 20, 2016.

Diagnosis: Four pairs of V-shaped chocolate-colored bars are found on the upper side of the body. Its body depth is 5.62 in standard length, but according to Randall (2001), it was 5.7-6.9. D, V/21; P, 15; V, I/5 br; A, I/17 br; C, 14 br; Li, 57; aLi, 5; bLi, 11; Br, 4 pair. According to Randall (2001), D, V/20-24; A, I/16-20, and according to Allen (1997) P, 14-21; V, I/5; Li, 38-84.

Description: The small, elongated, and cylindrical body is slightly convex dorsally. The head is medium and depressed to slightly triangular. The tip of the snout is flat with large eyes. A crescentic and slightly protractile mouth is situated terminally. Recurved caniform teeth are found in the outer row at the front of the jaws, and cardiform teeth are found on palatine and vomer. One spine and a serrated bone are present at the end of the operculum. A lateral line is completed, and slightly curved. The scales are ctenoid, rhomboidal, large, and overlapping. A large dorsal fin starts from the base of the pectoral fin and reaches up to the base of the caudal fin, with spines anteriorly. The large and elongated pectoral fin is situated ventrolaterally. The large pelvic fin is present at the forward. The large anal fin has spines onward, and 2/3 portion of the truncated caudal fin is scaly toward the base.

Color: Its body is dark brown dorsally and light-yellowish ventrally. Four large and four small chocolate spots alternate each other in a row on the lower side. 
The head is yellowish in color. A small orange-yellow line runs from below the eye along the operculum and up to the base of the pectoral fin. The edges of the scales of the upper 2/5 of the body are dark brown. The base and tip are white with two rows of black spots, and then a yellow line is found on the dorsal fin. The pectoral fin is orange-yellow. The pelvic and anal fins are light yellow pelvic. The caudal fin is also light yellow with a white margin and a black spot before the tip. It basally bears a black ocellus on the upper side and a black spot on the lower side (one above the other).

Habitat and Distribution: This species is found in open sand or muddy bottoms with a small reef or debris outcrops (Kuiter and Tonozuka 2001). Indo-West Pacific: Western Australia and the Indo-Australian archipelago. They are also recorded in the Philippines (Randall 2001).

\section{Pomadasys furcatus (Bloch and Schneider 1801) (Fig. 2J), local name is Dakina.}

Holotype: F1015SM05, male, $18.7 \mathrm{~cm}$ standard length; collected on October 2, 2015.

Diagnosis: Six brown horizontal stripes on the back and flanks. D, XII/16; P, 18; V, I/5; A, III/9; C, 20; Li, 68; aLi, 9; bLi, 17; Br 3. According to Smith and McKay (1986), D, XII/14-15; V, I/5; A, III/7-9.

Description: The large and elongated body is laterally flattened and convex dorsally. The large and blunt head has crescentic, protractile, and terminal mouth. Its chin has two pores and a medium pit. The lips are thick, and the jaws are large and equal. Caniniform teeth are present on jaws in several rows. The preopercle is posteriorly serrated. Operculum is with one indistinct spine. A lateral line is completed and curved. The scales are ctenoid, rhomboid, medium, and overlapping. A large dorsal fin is notched, residing in the middle of the body, with spines anteriorly, where all spines are embedded in pockets. The large and elongated pectoral fin is situated ventrolaterally. The large pelvic fin is positioned backward. The large anal fin contains spines onward; the second spine is strong, robust, and is the longest. The caudal fin is deeply emarginated.

Color: Its body is silver dorsally and whitish ventrally. Its head is blackish. Among six brown body stripes, the first stripe starts from slightly above the origin of spinous dorsal and joins with the starting base of the soft dorsal; the second stripe starts below the first one, bifurcated anteriorly, and reaches up to the anterior base of the soft dorsal; the third stripe starts from the nape, 
bifurcated anteriorly, and reaches up to the last basal portion of the soft dorsal fin; the fourth stripe starts from above the eye, bifurcated anteriorly, and reaches up to the caudal peduncle; the fifth stripe starts from behind the eye, runs along with the eye, and reaches up to the middle base of the upper caudalfin lobe; the sixth stripe starts from below the eye, runs along the upper base of the pectoral fin, and reaches up to the upper proximal base of the lower caudalfin lobe. The interspaces between the first three stripes are narrower than the stripes and broader than the stripes in the case of the last three stripes. The spinous part of the dorsal fin is yellowish with black tips; the soft part is blackish. The pectoral fin is brownish. The pelvic fin has a reddish base and a blackish tip. The anal and caudal fins are blackish.

Habitat and Distribution: This marine, reef-associated species inhabits coastal waters and frequents sandy areas near rocks (Smith and McKay 1986). Indo-West Pacific: Somalia (Sommer et al. 1996) Mozambique (Fischer et al. 1990) and Madagascar to Natal, South Africa, also from the Gulf of Aden to Sri Lanka, including the Red Sea. They were also recorded from Indonesia (Gloerfelt-Tarp and Kailola 1984).

\section{Siganus fuscescens (Houttuyn 1782) (Fig. 2K), the local name is Bristy Mas.}

Holotype: F1015SM06, male, $9.8 \mathrm{~cm}$ standard length, and with eight other individuals (all male, 6.9-19.7 $\mathrm{cm}$ total length and 4.28-97.72 $\mathrm{gm}$ weight), collected on October 2, 2015.

Diagnosis: Numerous pearly blue spots are found on the head and trunk. The body depth is 2.39 in standard length, and the last dorsal-fin spine is 1.66 in longest (4th - 8th spine longest) dorsal fin spine, and the last anal-fin spine 1.5 in longest (3rd \& 4th spine longest) anal-fin spine; D, XIII/10; P, 14; V, II/3; A, VII/9; C, 17; Br, 3. According to Woodland (1997), body depth 2.3-2.9 in standard length, last dorsal-fin spine 1.8 -2.5 in longest (4th -7th spine longest) dorsal fin spine, and last anal-fin spine 1.3-1.5 in longest (3rd spine longest) anal-fin spine; D, XIII/10; V, II/3; A, VII/9.

Description: The body is fairly slender and laterally compressed. Its head is small, and its dorsal profile is slightly concave above the orbit. The snout is short and blunt. The mouth is rounded, medium, inferior, and located subterminally. The jaws are medium and unequal. Incisiform teeth are present on both jaws in one row. A lateral line is completed and curved. The minute and 
elongated cycloid scales are overlapped and absent in the midthoracic region. A large dorsal fin is notched and situated in the middle of the body, has spines onward in which the $1^{\text {st }}$ spine is forward-directed; the fourth to eighth dorsal fin spines are the longest, considerably longer than (1.66 times) the last, slightly protruding from the pocket. The large and dagger-shaped pectoral fin is situated ventrolaterally. The pelvic fin is large and present at the forward with II spines (one inner and one strong outer spine, with three soft rays in between them) (Fig. 3K). The large anal fin has spines anteriorly; the last spine is 1.5 times in longest (third \& fourth) spine. Soft parts of dorsal and anal fins low. The caudal fin is emarginated.

Color: The body is dark brown dorsally and brown ventrally. The head is dark brown. Numerous pearly blue spots are found on the head and trunk, mainly round and pinhead size, but those in the mid-to-lower sides are slightly elongated horizontally; the least distance between neighboring spots are approximately the same as their diameter. A dark patch, a little smaller than the eye, is found just below the origin of the lateral line. The dorsal fin is blackish, the pectoral fin is yellowish, and the pelvic fin is brown. The anal fin is white with a black tip. The caudal fin has six incomplete pale bars on a dark brown background.

Habitat and Distribution: This marine, brackish, reef-associated; oceanodromous species (Riede 2004) is found in Western Pacific: Southern Korea, Southern Japan, Ogasawara Islands, Taiwan, Southern China, Malaysia, Singapore, Thailand, Andaman Islands, Indonesia, the Philippines, Yap, Palau, Pohnpei (Caroline Islands), Solomon Islands, Papua New Guinea, Vanuatu, New Caledonia, and Australia. Often misidentified as S. canaliculatus (Randall et al. 1990).

Acanthopagrus berda (Forsskal 1775) (Fig. 2L), the local name is Koi Coral. Holotype: F0216SM15; collected on February 17, 2016.

Diagnosis: Elongated and light yellowish pectoral fin. D, XI/12; P, 13; V, I/5; A, III/10; C, 22. According to Iwatsuki and Heemstra (2010), D, XI-XII/10-13; V, I/5; A, III/8-9.

Description: The body is elongated, and the head is short. Sharply curved concavity is observed on the ventral margin of the first two infraorbital above the posterior edge of the maxilla. No scales are found on the preopercular flange; molariform teeth are highly developed along both jaws, and the teeth row is 
strongly curved laterally at the rear of the lower jaw. The pectoral fin is elongated, reaching up to the anal pore. The caudal fin is deeply emarginated.

Color: The body is blackish. All fins are blackish except the pectoral fin, which is light yellowish.

Habitat and Distribution: This species is found in the Indian Ocean, South Africa, Mozambique, the Red Sea, Persian Gulf, India, Phuket, and Malaysia (Penang Island and Langkawi Island, near Singapore). Western Pacific specimens recorded as A. berda refers to Acanthopagrus pacificus (Iwatsuki et al. 2010).

\section{Gerres erythrourus (Bloch 1791) (Fig. 2M), the local name is Dum.}

Holotype: F1015SM17, male, $5.0 \mathrm{~cm}$ standard length, and with single another individual (female, $8.6 \mathrm{~cm}$ total length and $25 \mathrm{gm}$ weight), collected on October 2, 2015.

Diagnosis: The second dorsal fin spine is longer than the third spine. Body depth 2.27 in standard length; D, IX/10; P, 13; V, I/5; A, III/7; C, 20; Li, 51; aLi, 8; bLi, 15; Br, 4. According to Woodland (2001), body depth 1.9-2.3 in standard length; D, IX-X/9-11; A, III/6-8.

Description: Its body is deep, small, and compressed with an obtusely angled and elevated back. The head is small, and the snout blunt. In the interorbital area, the scales extend as a pair of horns, one on each side of the midline but does not extend on a broad front down to the nostrils. No scale is found on the premaxillary groove. The mouth is oblique and highly protractile, pointing downward with a medium mouth gap and placed termino-terminally. The jaws are small and equal with villiform teeth. A lateral line is completed and curved. The small and oval-shaped finely ctenoid scales are overlapped. A large dorsal fin is notched, with scaly base, with spines onward. The long and dagger-shaped pectoral fin is situated ventrolaterally, and its longest ray reaches the first analfin spine. The pelvic fin is small and positioned forward. The large anal fin has spines anteriorly; the second spine is long and robust. The caudal fin is strongly forked and homocercal, but the lobes are short and broadly rounded without pointed tips.

Color: Its body is silvery, tinged with light blackish dorsally. Indistinct fine dark stripes are found along scale rows. The head is silvery and blackish. The dorsal fin is silvery with a spiny black part, which is the tip membrane. Black spots are found on the fifth dorsal spine to the last ray base. The pectoral fin is 
whitish with yellowish base. The pelvic and anal fins are light yellowish with white tips. The caudal fin is whitish with black lower lobe tips.

Habitat and Distribution: This reef-associated; oceanodromous (Riede 2004), brackish, marine species found at a depth of 1-40 m (Myers 1991), mainly in the Indo-West Pacific: Madagascar to Australia also reported from Vanuatu (David 1985). Larvae reported in Japan as G. abbreviatus (Okiyama 1993).

\section{Lagocephalus spadiceus (Richardson 1845) (Fig. 2N), the local name is Futka.}

Holotype: F0416SM15, female, $13 \mathrm{~cm}$ standard length, and with three other individuals (all male, 11.9-14 cm total length, and 33.04-45 gm weight) collected on April 21, 2016.

Diagnosis: A patch of spinules are found on the back between the snout and halfway to the dorsal fin origin. D, 13; P, 17; A, 10; C, 9. According to Matsunuma et al. (2011), D, 11-13; P, 14-17; A, 10-12.

Description: The moderately sized body is globular, tapered, and dorsally convex toward the head. The head is large and blunt. The lines above and below the eye are circular and concave, respectively. Its nasal organ has two openings. The mouth is medium-sized, rounded, and positioned termino-terminally. The dorsal profile of the snout above the eye is convex. The jaws are small and unequal. They are modified to form a beak of four heavy, powerful teeth; two above and two below, which present overbite and seen a line in the middle of the two teeth and pointed (Fig. 3L). No opercular cover is seen; gill openings look like simple slits that are anterior to the pectoral fin. A lateral line is completed and steeply curved below the dorsal fin. No scales are found. A patch of spinules is seen on the back between the snout and halfway to the dorsal fin origin (Fig. 3M). This characteristic distinguishes $L$. spadiceus from L. lunaris, which has a patch of spinules on the back from behind the nostril to the dorsal fin origin (Fig. 3N). The belly is covered with spinules, starting from the position of the nostril and up to above the tip of the pectoral (half-length of pectoral). A small dorsal fin is situated near the tail and just the opposite of the anal fin and without spines. The pectoral fin is large, spread with a truncated tip, and placed ventrolaterally. No pelvic fins are found. The anal fin is small and contains no spine. The caudal fin is lunate.

Color: The body is light greenish dorsally with light yellowish side, and whitish ventrally. The head and the dorsal fin are light greenish, with the white lower one-third part. The pectoral fin is light yellowish, and the lower one-third 
is white. The anal fin is whitish, and the caudal fin is yellowish with a white margin and tip.

Habitat and Distribution: This marine, brackish, demersal, oceanodromous species (Riede 2004) is found in Indo-West Pacific: Red Sea, South Africa, Australia, and also introduced (Lessepsian) in Eastern Mediterranean, Israel, Lebanon, Iskenderun, Mersin, Aegean Sea (Tortonese 1979).

Psettodes bennettii (Steindachner 1870) (Fig. 20), local name is Baro Pata.

Holotype: F0416SM81, female, and $19.5 \mathrm{~cm}$ in standard length; collected on April 21, 2016.

Diagnosis: Irregular with several extremely small white spots present on the body dorsally. D, 52; P, 13; V, 5; A, 39; C, 15; uGr, 4; 1Gr, 12; Br, 7.

Description: The body is elongated, deep, and flat. The dorsal and ventral profiles are convex and moderate in size. The head is large and triangular. Both eyes are present on the dorsal side. The mouth is large, oblique, superior, and protractile. The jaws are large and unequal. Large caniniform teeth are present on both jaws (Fig. 3O), whereas cardiform teeth are found on palatine, and villiform pharyngeal teeth are also present. A lateral line is completed and curved. The small and circular cycloid scales are overlapped. A large dorsal fin is situated nearer to the head, which starts from the opercular opening and reaches up to just the opposite of the anal fin. The medium-sized and daggershaped pectoral fin is positioned ventrolaterally. The small pelvic fin presents anteriorly. The caudal fin is convex.

Color: The body and head are blackish dorsally and grayish ventrally. Twelve very small white spots are irregularly found on the body, mostly in the middle portion. On the lower portion of the upper jaw, one black spot is found. The dorsal fin is blackish tipped with white. The upper half of the pectoral fin is black, and the lower half is gray. The pelvic fin is gray with black tip. The anal and caudal fins are black with white tip.

Habitat and Distribution: This marine, demersal species is found at a depth of $15-50 \mathrm{~m}$, mainly on the continental shelf. This Eastern Atlantic species is distributed alongside the West coast of Africa from West Sahara to Liberia (Nielsen 1990).

Heteroconger perissodon (Bohlke and Randall 1981) (Fig. 2P); the local name is Kuchia.

Holotype: F0416SM69, male, with $41 \mathrm{~cm}$ standard length; collected on April 21, 2016. 
Diagnosis: Very minute black spots on the entire body. D, 286; P, 9; V, absent; A, 252.

Description: The body is tapered, and the head is pointed. Villiform teeth are found on the jaw and vomer. The dorsal and anal fins are confluent with the caudal fin.

Color: This species is black in color.

Habitat and Distribution: This marine, demersal, nonmigratory species is found at a depth of 1-35 m, mainly in Indo-West Pacific: Ambon, Indonesia, and Negros, the Philippines as well as in Andaman Islands (Allen and Erdmann 2012).

\section{CONCLUSION}

Sixty-seven species of coral-associated fish and 16 new species were recorded in St. Martin's Island, Bay of Bengal, Bangladesh, highlighting the increase in the ichthyofaunal biodiversity. The past records for coral fish diversity likely did not represent these new records due to the lack of extensive surveys, especially in the data-poor area. Species diversity records also show low representation for misidentification, resulting in synonymized species. Thus, the addition of potentially undescribed, even new species to the national record and world record of fishes from the northeastern part of the Bay of Bengal, Bangladesh, is possible with additional survey efforts and extensive studies. Coral reef bleaching events associated with global climate change increased the need for improved conservation measures to protect the fish-diversified coral reef ecosystem of St. Martin's Island.

Acknowledgement: We are thankful to the Ministry of Science and Technology, Government of the People's Republic of Bangladesh, for the financial support in this research work and to the local people of St. Martin's Island for helping in the collection of fish. Thanks also go to Jacqueline Wah for checking the English.

\section{LITERATURE CITED}

ALLEN, G.R. 1997. The marine fishes of tropical Australia and South-East Asia. Western Australian Museum, Perth, Western Australia. 292 pp.

ALLEN, G.R. and ERDMANN, M.V. 2012. Reef fishes of the East Indies. Perth, Australia: University of Hawai'i Press, Volumes I-III. Tropical Reef Research. DOI / ISBN/9780987260000. 
ALLEN, G.R. and TALBOT, J.H. 1985. Review of the snappers of the genus Lutjanus (Pisces Lutjanidae) from the Indo-Pacific with the description of a new species. Indo-Pacific Fishes 11: $87 \mathrm{pp}$.

ANDERSON, R.C., RANDALL, J.E. and KUITER, R.H. 1998. New records of fishes from the Maldives Islands, with notes on other species. Ichthyological bulletin 67 (2): 20-36.

BLOCH, 1790. Type species: Bodianus bodianus Bloch (= B. rufus) by tautonomy. 22 pp.

CARPENTER, K.E. 1987. Revision of the Indo-Pacific fish family Caesionidae (Lutjanoidea), with descriptions of five new species. Indo-Pacific Fishes 15: $56 \mathrm{pp}$.

CARPENTER, K.E., KRUPP, F., JONES, D.A. and ZAJONZ, U. 1997. Living marine resources of Kuwait, eastern Saudi Arabia, Bahrain, Qatar, and the United Arab Emirates. FAO species identification field guide for fishery purposes. 293 pp. +17 col. plates.

CERVIGON, F. 1994. Marine fish of Venezuela. Scientific Foundation Los Roques, Caracas, Venezuela. 3: 295 pp.

DAVID, G. 1985. Pche living and natural environment of Vanuatu's mangroves and fisheries interest. Ocanographie notes and documents. ORSTOM Mission of Port Vila 13: 67 pp.

FISCHER, W., SOUSA, I., SILVA, C., FREITAS, A.de., POUTIERS, J.M., SCHNEIDER, W., BORGES, T.C., FERAL, J.P. and MASSINGA, A. 1990. FAO species Identification of Fishing activities. Field guide of commercial marine species. Roma, FAO. 424 pp.

FRICKE, R., KULBICKI, M. and WANTIEZ, L. 2011. Checklist of the fishes of New Caledonia, and their distribution in the Southwest Pacific Ocean (Pisces). Stuttgarter Beitragezur Naturkunde A, Neue Serie. 4: 341-463.

GLOERFELT-TARP, T. and KAILOLA, P.J. 1984. Trawled fishes of southern Indonesia and northwestern Australia. Australian Development Assistance Bureau, Australia, Directorate General of Fishes, Indonesia, and German Agency for Technical Cooperation, Federal Republic of Germany. 407 pp.

GOMON, M.F. 2006. A revision of the Labrid fish genus Bodianus with descriptions of eight new species. Records of the Australian Museum, Supplement 30: 1-133.

IWATSUKI, Y. and HEEMSTRA, P.C. 2010. Taxonomic review of the Western Indian Ocean species of the genus Acanthopagrus Peters, 1855 (Perciformes: Sparidae), with description of a new species from Oman. Copeia. 2010 (1): 123-136.

IWATSUKI, Y., KUME, M. and YOSHINO, T. 2010. A new species, Acanthopagrus pacificus from the Western Pacific (Pisces, Sparidae). Bull. Natl. Mus. Nat. Sci., Ser. A. 36 (4): 115-130.

KIM, B.J. and NAKAYA, K. 2002. Upeneus australiae, a new goatfish (Mullidae: Perciformes) from Australia. Ichthyol. Res. 49 (2): 128-132. 
KUITER, R.H. and TONOZUKA, T. 2001. Pictorial guide to Indonesian reef fishes. Part 1. Eels Snappers, Muraenidae - Lutjanidae. Zoonetics, Australia. 1-302.

KURONUMA, K. 1961. A check list of fishes of Vietnam. United States Consultants, Inc.; International Cooperation Administration Contract-IV-153. Division of Agriculture and Natural Resources, United States Operations Mission to Vietnam. 66 pp.

LIESKE, E. and MYERS, R. 1994. Coral reef fishes. Indo-Pacific \& Caribbean including the Red Sea. Collins Pocket Guide. Haper Collins Publishers. 400 pp.

MATSUNUMA, M., MOTOMURA, H., MATSUURA, K., SHAZILI, N.A.M. and AMBAK, M.A. 2011. Fishes of Terengganu - East coast of Malay Peninsula, Malaysia. National museum of nature and science, University Malaysia Terengganu and Kagoshima University Museum, ix+251 pp.

MYERS, R.F. 1991. Micronesian reef fishes. Second Ed. Coral Graphics, Barrigada, Guam. 298 pp.

MYERS, R.F. 1999. Micronesian reef fishes: a comprehensive guide to the coral reef fishes of Micronesia, 3rd revised and expanded edition. Coral Graphics, Barrigada, Guam. 330 pp.

NIELSEN, J.G. 1990. Psettodidae. 1024 pp. In QUERO, J.C., HUREAU, J.C., KARRER, C., POST, A. and SALDANHA, L. (eds.) Check-list of the fishes of the eastern tropical Atlantic (CLOFETA). JNICT, Lisbon; SEI, Paris; and UNESCO, Paris. Vol. 2.

OLSEN, D.A., NELLIS, D.W and WOOD, R.S. 1984. Ciguatera in the Eastern Caribbean. Mar. Fish. Rev. 46 (1): 13-18.

OKIYAMA, M. 1993. An atlas of the early stage fishes in Japan. Koeltz Scientific Books, Germany. $1154 \mathrm{pp}$.

POR, F.D. 1978. Lessepsian migration. Springer-Verlag, Berlin, Heidelberg, New York. 228 p.

RAHMAN, A.K.A., KABIR, S.M.H., AHMED, M., AHMED, A.T.A., AHMED, Z.U., BEGUM, Z.N.T., HASAN, M.A. and KHONDKER, M. (eds.), 2009. Encyclopedia of Flora and Fauna of Bangladesh. Marine fishes. Asiatic Society of Bangladesh, Dhaka. 24: 485 pp.

RANDALL, J.E. 1978. Scaridae. In FISCHER, W. (ed.) FAO species identification sheets for fishery purposes. Western Central Atlantic (Fishing Area 31). Vol. 4.

RANDALL, J.E. 2001. Pinguipedidae (= Parapercidae, Mugiloididae). Sandperches. 3501-3510. In CARPENTER, K.E. and NIEM, V. (eds.) FAO species identification guide for fishery purposes. The living marine resources of the Western Central Pacific. Vol. 6. Bony fishes part 4 (Labridae to Latimeriidae), estuarine crocodiles. FAO, Rome.

RANDALl, J.E., ALLEN, G.R. and STEENE, R.C. 1990. Fishes of the Great Barrier Reef and Coral Sea. University of Hawaii Press, Honolulu, Hawaii. 506 pp.

RANDALL, J.E. and HOOVER, J.P. 1995. Scarus zufar, a new species of parrotfish from southern Oman, with comments on endemism of the area. Copeia: 683-688. 
RANDALl, J.E., WILliAMS, J.T., SMITH, D.G., KULBICKI, M., THAM, G.M., LABROSSE, P., KRONEN, M., CLUA, E. and MANN, B.S. 2003. Checklist of the shore and epipelagic fishes of Tonga. Atoll Res. Bull. Nos. 502 pp.

RIEDE, K. 2004. Global register of migratory species - from global to regional scales. Final Report of the R\&D-Project 80805081. Federal Agency for Nature Conservation, Bonn, Germany. 329 pp.

ROBINS, C.R. and RAY, G.C. 1986. A field guide to Atlantic coast fishes of North America. Houghton Mifflin Company, Boston, U.S.A. 354 pp.

SAHA, S., CHAKRABORTY, S., SEHRIN, S., MASUD, A.A., HABIB. K.A. and BAKI, M.A. 2018. New records of two Lutjanus species (Teleostei: Perciformes: Lutjanidae) with re-description of six lutjanids from Saint Martin's Island of the Bay of Bengal, Bangladesh. Bangladesh J. Zool.46 (2): 239-253. ISSN: 0304-9027 (print) 2408-8455 (online).

SARKER, M.M., BAKI, M.A. and SARKER, A. 2015. Taxonomic study of coral fish of Saint Martin's Island in the Bay of Bengal (Abstract). Marine conservation and blue economy symposium, 2015. Krishibid Institution of Bangladesh, Dhaka. http://www.saveoursea.social/

SHAFI, M. and QUDDUS, M.M.A. 2003. Fisheries Resources in the Bay of Bengal. Kabir publication, 38/3 Bangla Bazar, Dhaka. 150 pp.

SMITH, C.L. 1997. National Audubon Society field guide to tropical marine fishes of the Caribbean, the Gulf of Mexico, Florida, the Bahamas, and Bermuda. Alfred A. Knopf, Inc., New York. 720 pp.

SMITH, M.M. and MCKAY, R.J. 1986. Haemulidae. pp. 564-571. In SMITH, M.M. and HEEMSTRA, P.C. (eds.) Smiths' sea fishes. Springer-Verlag, Berlin.

SOMMER, C., SCHNEIDER, W. and POUTIERS, J.M. 1996. FAO species identification field guide for fishery purposes. The living marine resources of Somalia. FAO, Rome. $376 \mathrm{pp}$.

TOMASCIK, T. 1997. Management plan for coral resources of Narikel jinjira (St. Martin's Island), national conservation strategy implementation project-1, Ministry of Environment and Forest, Government of Bangladesh. 126 pp.

TORTONESE, E. 1979. Tetraodontidae. 645-646. In Hureau J.C. and Monod Th. (eds.) Check-list of the fishes of the northeastern Atlantic and of the Mediterranean (CLOFNAM). UNESCO, Paris. Vol. 1.

UIBLEIN, F. and HEEMSTRA, P.C. 2010. A taxonomic review of the Western Indian Ocean goatfishes of the genus Upeneus (Family Mullidae), with descriptions of four new species. Smithiana. 11: 35-71.

WOODLAND, D. 1997. Siganidae. Spinefoots, Rabbitfishes. 3627-3650. In CARPENTER, K.E. and NIEM, V. (eds.) FAO Identification Guide for Fishery Purposes. The Western Central Pacific. 837 pp. 
WOODLAND, D. 2001. Gerreidae. Silver-biddies. 2946-2960. In CARPENTER, K.E. and NIEM, V. (eds.) FAO species identification guide for fishery purposes. The living marine resources of the Western Central Pacific. Vol. 5. Bony fishes part 3 (Menidae to Pomacentridae). FAO, Rome.

(Manuscript received on 14 February, 2020 revised on 10 November, 2020) 